\title{
CONSECUENCIAS DEL FRANQUISMO EN LA ESPAÑA DEMOCRÁTICA: LEGISLACIÓN, EXHUMACIONES DE FOSAS Y MEMORIA
}

\author{
CONSEQUENCES OF FRANCO'S REGIME FOR DEMOCRATIC SPAIN: \\ LEGISLATION, EXHUMATION OF GRAVES AND MEMORY \\ Julián Chaves-Palacios* \\ Universidad de Extremadura, Cáceres
}

\begin{abstract}
RESUMEN: Legislación, investigación, exhumación de fosas comunes y memoria constituyen variables que en España deben marchar unidas para responder a demandas sociales que no admiten dilación. Juntas han tratado de dar respuesta a las reivindicaciones de las familias y asociaciones que les representan en su exigencia de actuaciones sobre cuestiones que afectan directamente a los Derechos Humanos más elementales. Conjunto de contenidos que ha merecido la atención de la administración pública, tanto nacional como autonómica, que han procedido a aprobar leyes y normas con objeto de dar cumplida contestación a ese requerimiento ciudadano. Decisiones que con frecuencia se han visto acompañadas de controvertidos debates. Contenidos que son analizados en este artículo que pretende ofrecer una panorámica sobre esas iniciativas legales tras la muerte del dictador, en relación a las consecuencias de la guerra civil y régimen posterior y sus repercusiones en la sociedad.
\end{abstract}

PALABRAS CLAVE: historia; franquismo; guerra civil; legislación; represión; fosas comunes; memoria histórica.

\begin{abstract}
Memory, legislation, research and exhumation of mass graves are variables that should be evaluate together with the aim to answer the social demands that are still waiting in Spain. These areas, as a whole, have tried to respond the claims of the relatives of the victims of the Civil War and the Dictatorship and the memorial associations, in the defense of Human Rights. These contents have drawn the attention of governments and institutions, that have implemented national and regional laws and normative, to answer the claims of their citizens. A decision that have generated controversial debates in the society. In this paper we analyze these contents with the aim to provide an overview of the legal initiatives, developed from the death of the dictator Francisco Franco onwards, and evaluate their consequences and impact in the society.
\end{abstract}

KEYWORDS: History; Franco's repression; Civil War; mass graves; legislation; historical memory.

* Correspondencia a: Julián Chaves Palacios. Universidad de Extremadura. Facultad de Filosofía y Letras. Departamento de Historia. Avenida de la Universidad s/n. Cáceres 10071 - jchapal@unex.es - https://orcid.org/0000-0001-6569-4750.

Cómo citar: Chaves-Palacios, Julián. «Consecuencias del franquismo en la España democrática: legislación, exhumaciones de fosas y memorian; Historia Contemporánea, 60, 509-538. (https://doi.org/10.1387/hc.20311).

Recibido: 5 noviembre, 2018; aceptado: 17 enero, 2019.

ISSN 1130-2402 - eISSN 2340-0277 / (C) 2019 UPV/EHU 


\section{Introducción}

Con la muerte de Francisco Franco el 20 de noviembre de 1975 desapareció la persona que había protagonizado la historia española en las últimas décadas, pero su ausencia no erradicó los problemas heredados. Uno de ellos: la memoria y el legado de la guerra civil de 1936 constituían una seria dificultad para la necesaria reconciliación en España. Diversos factores influyeron para que esta cuestión permaneciera pendiente al iniciarse la Transición política. Uno de ellos fue la premeditada instrumentalización que de la historia y de la memoria de esa contienda armada y régimen posterior realizó el franquismo. Asimismo su firme propósito por hacer desaparecer cualquier vestigio o referencia que hiciera alusión a la Segunda República ${ }^{1}$, que contrasta con la permanente sublimación y legitimación del sistema político impuesto tras la victoria por las armas.

Planteamientos que se mantuvieron en el tiempo, descartando de forma deliberada cualquier iniciativa que pretendiera potenciar la convivencia entre todos los españoles, tanto vencedores como vencidos y otros que no eran ni lo uno ni lo otro. Comportamiento en consonancia con todo autoritarismo, en que el pensamiento único prevalece sobre cualquier otra alternativa. Sin embargo, el fallecimiento del dictador abrió un nuevo tiempo en que se imponía, por encima de otras veleidades, la reconciliación como una necesidad para lograr la convivencia pacífica entre los españoles

Era necesario superar ese pasado traumático y no utilizarlo como arma arrojadiza en función de conveniencias de unos y otros. No se podía volver a repetir, por tanto, una experiencia que tanto dolor y sufrimiento había llevado al suelo patrio. Asimismo este contexto permitía atisbar la percepción de un sentimiento de culpa bastante generalizado en la sociedad que daba sus primeros pasos en la Transición. Todo ello en el convencimiento de que lo sucedido en el 36 no volvería a repetirse y se imponía la renuncia a utilizarlo políticamente y en función de conveniencias partidistas. Había que evitar esa deriva si se deseaba caminar, como así se hizo, hacia un sistema democrático en que estuvieran representados todos los españoles.

Y, evidentemente, ese proceso exigió un pacto tácito en que se imponía dejar a un lado ese pasado. Pacto que tenía como trasfondo la idea de la reconciliación, de no abrir viejas heridas relacionadas con la guerra civil y el franquismo. Y si bien no pudo satisfacer a unos y a otros, sin embargo facilitó

${ }^{1}$ Chaves, 2009, pp. 107-142 (para esta cita p. 141). 
el necesario entendimiento ${ }^{2}$. Y a tenor de lo sucedido con posterioridad, ese deseo público se cumplió con acierto, como lo ha demostrado la experiencia democrática ulterior, sin precedentes en la historia de España.

Sistema de libertades que se fue cimentando en los años de Transición dejando a un lado, al menos en el debate público, la guerra civil y sus graves consecuencias para los vencidos. Posicionamiento que no impidió que el recuerdo de esa contienda armada estuviera presente en muchas personas y que suscitara y suscite no pocos resentimientos y polémicas. Y es que en pleno siglo XXI, más allá de la evolución registrada en el conocimiento histórico de esos años, lo cierto es que su recuerdo sigue muy presente en la sociedad española. Como afirma el investigador González Ruibal: «la guerra civil está muy lejos y muy cerca al mismo tiempo» ${ }^{3}$.

Máxime cuando existen cuestiones pendientes de resolver, siendo una de ellas la existencia de fosas comunes a causa de la represión franquista en la guerra civil, que pese al tiempo transcurrido no se ha procedido a su exhumación, continuando bajo tierra los restos de las víctimas ${ }^{4}$. Oprobio que exige una solución, como demandan los familiares afectados y las asociaciones memorialistas que les representan. Todo ello a pesar de que en estos decenios democráticos, prácticamente desde sus inicios, los diferentes Gobiernos han ido aprobando leyes destinadas a atenuar las consecuencias de la guerra sobre los ciudadanos.

Corpus legislativo de diferente procedencia y condición que comenzó tras la muerte del dictador, aprobándose ya en la Transición una serie de iniciativas legales de indudable trascendencia posterior. Y en plena democracia asistimos a una evolución legislativa desigual, que sobre todo ha adquirido verdadera carta de naturaleza en el siglo actual ${ }^{5}$, cuando han visto la luz leyes y decretos de ámbito estatal que se han visto acompañados, cuando no completados, por otros abanderados por determinadas comunidades autónomas.

Abanico legal sobre el que abundaremos en el presente trabajo, partiendo de la hipótesis de que en pleno siglo XXI los frecuentes debates y controversias sobre la contienda armada de 1936 y el franquismo muestran que el legado de ese pasado está muy presente en parte de la ciudadanía española ${ }^{6}$. Consecuencias que el paso del tiempo no ha conseguido su-

\footnotetext{
2 Pérez Serrano, 2004, pp. 93-122.

3 González Ruibal, 2016, p. 30.

4 Ferrándiz, 2007.

5 Pasamar, 2016.

${ }^{6}$ Espinosa, 2015.
} 
perar pese a iniciativas como la aprobación de una serie de leyes que han tratado de paliar sus efectos.

El análisis de esa legislación y su grado de incidencia social constituyen nuestro principal objeto de trabajo a lo largo de estas páginas, conscientes del riesgo que comporta realizar una exposición sumaria de esas leyes sin la profundización que cada una requiere. Pero se trata de efectuar una radiografía, una puesta en común de esa normativa sobre temática tan específica, sin olvidar en su tratamiento contenidos tan pertinentes como la memoria de los vencidos o la misma exhumación de fosas comunes.

\section{Respuesta legislativa a las demandas ciudadanas durante la Transición}

Dentro del recorrido histórico que deseamos exponer sobre esa legislación tras la muerte del general Franco $^{7}$, tenemos como punto de partida la Transición política ${ }^{8}$, o para ser más exactos la llegada a la presidencia del Gobierno de España de Adolfo Suárez. Desde entonces, como puede apreciarse en el cuadro que se acompaña sobre legislación en ese período, comenzaron a ser aprobadas una serie de leyes entre las que destacamos, en primer lugar, la 46/1977 conocida como Ley de Amnistía, en la que resaltamos sus efectos no sólo tras su promulgación, sino también con posterioridad, como lo demuestra que incluso en la actualidad haya merecido la atención tanto por su contenido como por sus consecuencias ${ }^{9}$.

Y es que estamos ante un texto legal que vio su aprobación en un año plagado de acontecimientos como fue 1977, con la celebración de las primeras elecciones generales tras la muerte del general Franco e iniciativas gubernamentales como la legalización del PCE que tanto alteraron a los defensores del franquismo ${ }^{10}$. Contexto político que dificultaba enormemente plantear la exigencia de responsabilidades penales a dirigentes del régimen anterior por su comportamiento punitivo. Y es que la Ley de Amnistía, pese a la polémica que ha originado con posterioridad, en aquellos tiempos se concibió como un medio para tratar de acabar con la violencia terrorista, pero también como una forma de potenciar la necesaria reconciliación ${ }^{11}$.

\footnotetext{
7 Sánchez Marroyo y Chaves, 2008, pp. 101-123.

${ }^{8}$ Hernández Castrillo, 2010, pp. 89-137.

9 Ysàs, 2010, pp. 31-57.

10 Pinilla, 2017, p. 211 y ss.

11 Molinero, 2007, pp. 201-225.
} 


\section{Cuadro 1}

Textos legislativos estatales aprobados durante la Transición política relacionados con las consecuencias de la Guerra Civil

\begin{tabular}{|c|c|c|}
\hline Procedencia & Fecha & Concepto \\
\hline $\begin{array}{l}\text { Jefatura del Estado. Ley } \\
46 / 1977\end{array}$ & BOE 17-X-1977 & Sobre Amnistía. \\
\hline $\begin{array}{l}\text { Jefatura del Estado. Real Decre- } \\
\text { to Ley } 6 / 1978 \text { y Ley } 10 / 1980 \\
\text { modificando Decreto } 6 / 1978\end{array}$ & $\begin{array}{l}\text { BOE 7-III-1978 y } \\
B O E \text { 26-III-1980 }\end{array}$ & $\begin{array}{l}\text { Se regula la situación de los militares } \\
\text { que tomaron parte en la guerra civil. }\end{array}$ \\
\hline $\begin{array}{l}\text { Jefatura del Estado. Real Decre- } \\
\text { to Ley } 35 / 1978\end{array}$ & $B O E$ 18-XI-1978 & $\begin{array}{l}\text { Concesiones de pensiones a los fami- } \\
\text { liares de los españoles fallecidos como } \\
\text { consecuencia de la guerra 1936-1939. }\end{array}$ \\
\hline $\begin{array}{l}\text { Jefatura del Estado. Real Decre- } \\
\text { to- Ley } 43 / 1978\end{array}$ & BOE 22-XII-1978 & $\begin{array}{l}\text { Reconocimiento beneficios económi- } \\
\text { cos a los que sufrieron lesiones y muti- } \\
\text { laciones en la guerra civil española. }\end{array}$ \\
\hline Jefatura del Estado. Ley 5/1979 & BOE 28-IX-1979 & $\begin{array}{l}\text { Sobre reconocimiento de pensiones, } \\
\text { asistencia médico-farmacéutica y asis- } \\
\text { tencia social en favor de las viudas } \\
\text { y demás familiares de los españoles } \\
\text { fallecidos como consecuencia o con } \\
\text { ocasión de la guerra civil. }\end{array}$ \\
\hline $\begin{array}{l}\text { Jefatura del Estado. Ley } \\
10 / 1980\end{array}$ & BOE 10-VII-1980 & $\begin{array}{l}\text { Sobre pensiones a mutilados excomba- } \\
\text { tientes de la zona republicana. }\end{array}$ \\
\hline $\begin{array}{l}\text { Ministerio de Cultura. Orden de } \\
\text { 31-VII-1980 }\end{array}$ & BOE 5-IX-1980 & $\begin{array}{l}\text { Creación del Patronato de la sección } \\
\text { de la guerra civil del Archivo Histórico } \\
\text { Nacional. }\end{array}$ \\
\hline $\begin{array}{l}\text { Jefatura del Estado. Real Decre- } \\
\text { to Ley } 8 / 1980\end{array}$ & BOE 1-X-1980 & $\begin{array}{l}\text { Sobre fraccionamiento en el pago de } \\
\text { atrasos de pensiones derivadas de la } \\
\text { guerra civil. }\end{array}$ \\
\hline $\begin{array}{l}\text { Presidencia del Gobierno. Real } \\
\text { Decreto 391/1982 }\end{array}$ & BOE 5-III-1982 & $\begin{array}{l}\text { Integración en el régimen general de la } \\
\text { Seguridad Social, a efectos de asisten- } \\
\text { cia sanitaria y servicios sociales, a los } \\
\text { mutilados excombatientes de la zona } \\
\text { republicana. }\end{array}$ \\
\hline Jefatura del Estado. Ley 6/1982 & BOE 3-IV-1982 & $\begin{array}{l}\text { Pensiones a los mutilados civiles de } \\
\text { guerra. }\end{array}$ \\
\hline
\end{tabular}

Fuente: Hernández Castrillo, 2010, pp. 89-137. 
Independientemente del peso específico que tuvo en su aprobación la violencia en Euskadi y la esperanza de una posible solución con la liberación de presos de ETA a través de la puesta en marcha de esta Ley $^{12}$, lo cierto es que de forma recíproca la amnistía se extendió a todos los funcionarios susceptibles de ser culpables de incurrir en lo que se conoce como «actos de violencia institucional» durante el régimen anterior. Su aprobación en las Cortes fue festejada por los partidos antifranquistas por lo que significaba de «primera y contundente declaración de ilegitimidad de la dictadura» ${ }^{13}$, mientras que las formaciones próximas a los postulados franquistas se mostraron remisas a su aprobación.

Sin embargo, años después esta Ley, más allá de lo que supuso de poner en libertad a menos de un centenar de reclusos condenados por acciones terroristas, se ha interpretado como el texto que garantizó la impunidad de los delitos cometidos por los dirigentes franquistas, al no permitir juzgar a los responsables de violar derechos fundamentales en la dictadura, a no convertir, en suma, la violencia represiva practicada en épocas pretéritas en instrumento en la lucha política ${ }^{14}$.

Con posterioridad, sin embargo, se ha subordinado ese aspecto crucial en aquellos tiempos tan convulsos y se ha hecho especial énfasis en que permitió la impunidad de autoridades y funcionarios comprometidos con hechos delictivos durante el régimen de Franco ${ }^{15}$. Incluso, en relación a esa última lectura, ha sido objeto de críticas por parte de formaciones políticas de izquierdas, que convencidas del obstáculo que ha supuesto su existencia no han dudado en presentar proposiciones no de ley en el Congreso de los Diputados con objeto de reformarla ${ }^{16}$ e incluso derogarla ${ }^{17}$, que no han prosperado ${ }^{18}$.

12 Juliá, 2008.

13 Ysàs, 2010, pp. $31-57$ (p. 55 para esta cita).

14 Gil, 2009.

15 Espuny et al., 2007.

16 En concreto, la propuesta fue presentada en el Congreso por el grupo de Unidos Podemos-En Comú y pretendía modificar la ley para que «los torturadores del franquismo no se les pueda aplicar esta norma, lo que permitiría que sean juzgados». Fue rechazada ante el voto en contra de PP, PSOE y Ciudadanos. Diario Público, 20-XII-2016.

17 En este caso fue una campaña abanderada por Izquierda Unida con vistas a su derogación. EL PAÍS, 24-I-2017.

18 También se ha puesto de actualidad esta Ley por otras razones, como la decisión del entonces juez de la Audiencia Nacional, Baltasar Garzón, de promulgar un Auto 
Pero dejando a un lado la Ley 46/1977 y sus consecuencias en la actualidad, es preciso destacar otra de las iniciativas legales aprobadas en la Transición, en este caso dos años después que la anterior. Se trata de la Ley 5/1979 por la que se concedían pensiones y asistencia médico-farmacéutica a «las viudas de los españoles fallecidos como consecuencia o con ocasión de la Guerra Civil» ${ }^{19}$. Los «expedientes de viudedad» tramitados en su aplicación los solicitaron, por lo general, mujeres viudas a causa de actos represivos franquistas en la guerra civil y posguerra, al contemplar en su articulado la posibilidad de obtener una pensión.

Uno de los trámites a realizar era recoger testimonios sobre la peripecia vital del difunto hasta su muerte. Como ejemplo, a continuación exponemos uno de ellos, relativo al vecino del municipio extremeño de Peraleda de la Mata, Casto Miguel Martín:

«El 28 de agosto de 1936 fue controlado el pueblo de Peraleda de la Mata por las fuerzas nacionales y a los pocos días detenidos varios vecinos que fueron encarcelados en el calabozo municipal. Entre los detenidos se encontraba Casto Miguel Martín. En distintos días, a estos presos los ejecutaron en el puente sobre el Tajo, en la carretera de Peraleda de la Mata a Bohonal de Ibor, arrojando sus cadáveres al río. En concreto, el 6 de septiembre de 1936 fusilaron a siete de los detenidos, entre ellos a Casto, y el 12 de ese mismo mes acabaron con la vida de los diez que quedaban en el calabozo.» ${ }^{20}$

Como puede apreciarse estamos ante una declaración de indudable interés histórico al permitir conocer lo sucedido a represaliados sobre los que, por lo general, no existía ni referencia documental ni testimonial sobre su paradero ${ }^{21}$. Ley que gozó de buena acogida en la España de la Transición aunque se desconocen datos sobre el número de solicitantes que se dirigieron a los ayuntamientos a cumplimentar los preceptivos trámites. En este sentido, pese a la posibilidad de obtener una pensión, es

en octubre de 2008 por el que se declaraba competente en casos de crímenes contra la humanidad cometidos por el franquismo. Véase este Auto en http://estaticos.soitu.es/ documentos/2008/10/auto_memoria_historica.pdf

19 Boletín Oficial del Estado (en adelante BOE), 28-IX-1979.

20 Archivo Municipal de Peraleda de la Mata, Legajo Expedientes de Viudedad.

21 Chaves, 1995, p. 178 y ss. 
difícil saber si todos los afectados se decidieron a solicitarla pues no en vano hacerlo significaba rememorar hechos que durante décadas se vieron obligados a callar, en no pocos casos bajo amenazas.

Pero independientemente del número de personas que se decidieron a solicitar estas ayudas, lo relevante desde un punto de vista histórico ha sido su utilidad para ir desentrañando el complejo entramado represivo franquista y sus consecuencias. Aportación importante pues acervos documentales como el generado por esta Ley, junto a otros, han permitido identificar desaparecidos y localizar fosas comunes repartidas por toda la geografía española. Y deseamos abundar en esta afirmación pues entendemos que este tipo de fondos documentales han contribuido a fundamentar las investigaciones desarrolladas con posterioridad sobre el alcance de estas prácticas sobre la población republicana.

Igualmente cabe destacar la aprobación en este mismo período de Transición, según se recoge en citado cuadro, de leyes que regulaban la situación de los militares que tomaron parte en la guerra civil; concesión de retribuciones a quienes sufrieron lesiones y mutilaciones en la guerra; con la novedad de incluir también a excombatientes republicanos, que fueron integrados en la seguridad social. En suma, tras la muerte del dictador, en España comenzaron a aprobarse leyes que trataban de compensar, al menos económicamente, a quienes sufrieron las consecuencias de la guerra y régimen político posterior.

\section{Ralentización política y legislativa en democracia}

Con los inicios de la democracia alcanzaba el Gobierno una de las formaciones políticas que fueron derrotadas en la guerra civil, con todo el significado histórico y político que ello entrañaba para los españoles. Un nuevo tiempo histórico marcado por el protagonismo de los socialistas que permanecieron al frente del Ejecutivo desde finales de 1982 hasta $1996^{22}$.

Periodo en que las cuestiones relacionadas con las consecuencias de la guerra civil y el franquismo fueron relegadas a un plano residual, como se puede deducir de la escasa legislación que se aprobó sobre esta materia no sólo en esos catorce años sino hasta finalizar el siglo. Y es que, como

22 Soto y Avilés, 2013. 
se puso de manifiesto en la conmemoración del cincuentenario del inicio de la guerra civil en 1986, dos vertientes destacaban en el panorama español respecto a la memoria e historia de ese conflicto armado:

«Por un lado quienes defendían que había que cerrar el tema, que todo estaba ya dicho y pretendían silenciar de nuevo este trauma, visión con la que se identificaban los vencedores y sus herederos, aunque no sólo ellos; y la de quienes propugnaban que aún quedaba mucho por decir, por aprender y por rescatar de aquel período traumático.» ${ }^{23}$

Posiciones distantes sobre las que no se trataba de llegar a un consenso, o al menos éste no se potenciaba desde instancias políticas. Así cabe entender actitudes de líderes tan destacados en esos años como el socialista y presidente del Gobierno durante todo este período de dominio del PSOE, Felipe González Márquez, que llegó a argumentar que para cimentar la necesaria reconciliación de los españoles y asentar la democracia, se imponía «no remover los viejos rescoldos bajo los cuales seguía habiendo fuego» ${ }^{24}$. Consideramos que esa frase define adecuadamente el comportamiento de sus gobiernos en relación a la guerra civil y el franquismo, de su firme deseo de no remover este pasado, evitando recuerdos que pudieran perturbar la necesaria convivencia entre los españoles ${ }^{25}$.

$\mathrm{Y}$ en consonancia con esos deseos cabe entender que, a diferencia de la etapa política anterior, en un período que abarca casi dos décadas sólo cabe resaltar cinco leyes relacionadas con el objeto de estudio, con el matiz que dos fueron aprobadas durante el Gobierno del Partido Popular (1996-2000). En concreto, de las aprobadas a mediados de los ochenta, la primera tiene continuidad con las iniciativas aprobadas en la etapa anterior, al hacer referencia a reconocimientos a quienes durante la guerra civil formaron parte del ejército, fuerzas del orden y miembros del cuerpo de carabineros de la República ${ }^{26}$.

La otra guarda relación con la cesión de bienes incautados como consecuencia de la contienda armada de 1936 a las organizaciones sindi-

23 Cuesta, 2008, p. 321.

${ }^{24}$ González y Cebrián, 2001.

25 Aguilar, 2008, pp. 420-422.

26 BOE, 1-XI-1984. 
cales democráticas ${ }^{27}$. En concreto fue en septiembre de ese año cuando la presidencia de la Junta de Defensa en Burgos aprobó el decreto 108, que no sólo ilegalizaba los partidos y organizaciones afines al Frente Popular, sino que también ordenaba la incautación de sus «bienes muebles, inmuebles, efectos y documentos de su pertenencia» ${ }^{28}$, que pasaron a propiedad del nuevo Estado franquista. Bienes que a través de esta ley de 1984 y tras la preceptiva demostración documental, se pudieron reintegrar al patrimonio de los sindicatos.

Y la tercera ley a destacar promovida por los socialistas: la concesión de nacionalidad española a los combatientes de las Brigadas Internacionales en la Guerra Civil española, presenta como novedad que su publicación en el $B O E$, pese a que el Real Decreto data del 19 de enero, se produjo dos días después de perder el PSOE las elecciones generales del 3 de marzo de 1996, que ganó el Partido Popular y le relevó al frente del Gobierno.

Se tramitó a propuesta del ministerio de Justicia e Interior, que tenía como titular a Juan Alberto Belloch, y en su preámbulo se exponen las razones de su aprobación: «reconocer la labor en pro de la libertad y de la democracia llevada a cabo por los voluntarios integrantes de las Brigadas Internacionales durante la guerra española de 1936 a 1939» 29 . Era una reivindicación que venía de tiempo atrás que se encontró con el obstáculo de que el acceso a la nacionalidad mediante esta Ley estaba sujeto al requisito de tener que renunciar a la que tenían entonces, exigencia que obligó a la mayoría de ellos a desistir de la ciudadanía española.

Una década después, tras ser aprobada la conocida como Ley de «Memoria Histórica» en diciembre de $2007^{30}$, se dio respuesta a esta cuestión al establecer en su artículo 18 la concesión de la nacionalidad española a los voluntarios integrantes de las Brigadas Internacionales, eliminando el requisito de tener que renunciar a su anterior nacionali$\operatorname{dad}^{31}$.

27 BOE, 14-I-1986.

${ }_{28}$ Boletín Oficial de la Junta de Defensa Nacional de España, 16-IX-1936.

${ }^{29}$ BOE, 5-III-1996.

30 BOE, 27-XII-2007.

31 Un año después, mediante Real Decreto 1792/2008 de fecha 3 de noviembre de 2008, se dio ejecución a lo dispuesto en referido artículo, abriendo las puertas a los pocos sobrevivientes de las brigadas a poder tener pasaporte y plena ciudadanía hispana. $B O E$, 17-XI-2008. 
Y completamos nuestro análisis sobre legislación antes de finalizar el siglo XX, haciendo referencia a las dos leyes impulsadas por gobiernos del Partido Popular. Una de ellas se refiere a la «restitución o compensación a los partidos políticos de bienes incautados en aplicación de la normativa sobre responsabilidades políticas del período 1936-1939»32. Si la ya referida de 1984 se ocupaba de las organizaciones sindicales republicanas, en este caso se destinaba a restituir los bienes de las formaciones políticas frentepopulistas.

La otra es la creación del Archivo General de la Guerra Civil en la ciudad de Salamanca ${ }^{33}$. En sus dependencias se depositaría la documentación correspondiente a la sección «Guerra Civil» hasta entonces en el Archivo Histórico Nacional en la capital de España ${ }^{34}$. Y también en Salamanca, ya en 2007, se creó el Centro Documental de la Memoria Histórica que sustituyó al Archivo General, teniendo entre sus objetivos «reunir y recuperar todos los fondos documentales, testimonios orales y por cualquier otro medio relativos al período histórico comprendido entre 1936 y $1978 »^{35}$.

En suma, las iniciativas legales sobre la guerra civil y dictadura durante estos dos primeros decenios de democracia se caracterizaron por su diferente procedencia y condición, mostrando de forma fehaciente el escaso interés político por abundar en este contenido. Evolución que contrasta con los avances obtenidos durante estas dos décadas por la investigación histórica, hasta el punto que en el decenio de los ochenta se registró el mayor número de publicaciones sobre la contienda armada de 1936 del último cuarto de siglo $\mathrm{xx}^{36}$.

La paulatina consolidación de un régimen de libertades en el país, el acceso de los investigadores a archivos públicos que no se habían podido consultar o la celebración de efemérides tan señaladas como cumplir medio siglo desde inicios de la guerra civil (1986) o de su conclu-

32 BOE, 16-XII-1998.

33 BOE, 13-III-1999.

34 Es preciso indicar sobre esta documentación, que años después se vio inmersa en la polémica tras la decisión del Gobierno de José Luis Rodríguez Zapatero de restituir a la Generalitat de Cataluña de los documentos incautados con motivo de la guerra civil que se encontraban en el centro archivístico de Salamanca. Chaves, 2007, pp. 191-212.

35 BOE, 15-VI-2007.

36 Ruiz y Riesco, 1999, p. 183. 
sión (1989) se convirtieron en estímulos suficientes para entender esa eclosión de libros sobre este pasado y sus consecuencias.

Publicaciones en las que cabe destacar que se fueron abriendo paso, junto a las obras de carácter general, las monografías provinciales y locales que aportaron novedosos datos sobre uno de los contenidos hasta entonces menos tratado por la historiografía: la represión franquista ${ }^{37}$. Textos que con sus aportaciones pusieron en cuestión la información que hasta entonces se disponía sobre las pérdidas de vidas humanas a causa de las prácticas represivas practicadas por el bando vencedor ${ }^{38}$, de forma que casi todas las comunidades autónomas vieron publicados estos años estudios en que se abordaba esta temática.

Sin entrar en valoraciones sobre calidad e importancia de cada uno de ellos consideramos que una de sus aportaciones consistió en rellenar el vacío existente en lo relativo a obras territoriales sobre la guerra civil y posguerra en todo el país. Asimismo dar a conocer cifras de fallecidos a causa de ese tipo de actividades tan deleznables que han permitido ir construyendo el complicado puzle de las muertes originadas por la represión $^{39}$. De forma paralela esos estudios han posibilitado localizar fosas comunes con restos de personas pasadas por las armas y repartidas por toda la geografía hispana así como la preceptiva identificación de los afectados. Ubicación e identificación que han resultado fundamentales para el ingente número de exhumaciones que se han registrado en España con el inicio del siglo XXI.

\section{Siglo XxI: ley de Memoria Histórica}

De forma paralela, ese proceso se ha visto acompañado por iniciativas políticas y judiciales así como movimientos asociativos que han dado a estos inicios de centuria un giro sustancial en relación a este pasado traumático. Así cabe interpretar iniciativas políticas como la de noviembre de 2002 en que por unanimidad la Comisión Constitucional del Parlamento de España aprobó una proposición de ley de condena de la sublevación de

37 Chaves, 2000, pp. 409-430. ;

38 Salas, 1977.

39 Chaves, 2007, pp. 409-430. 
julio de 1936, reconocimiento a las víctimas de la dictadura e impulso a reabrir las fosas comunes ${ }^{40}$.

Consenso de todas las organizaciones políticas que formaban parte del parlamento español en ese periodo que no volvió a registrarse con posterioridad, poniendo de manifiesto la falta de entendimiento que sobre este asunto ha gravitado entre las opciones conservadoras y de izquierdas españolas. Disenso que no evitó, empero, que se siguiera legislando sobre las consecuencias de la guerra civil y el franquismo, especialmente tras el triunfo electoral del PSOE en las elecciones generales de 2004.

El cuadro que exponemos sobre legislación en la primera década del siglo actual es suficientemente ilustrativo, teniendo su punto de partida citado año mediante decreto por el que se creaba una Comisión Interministerial para el estudio de las víctimas originadas en la contienda armada de 1936 y franquismo, y concluyendo en 2010 con la aprobación del reglamento de acceso a los archivos de los tribunales militares. Y entremedias reconocimientos económicos, medidas de reparación e incluso declaraciones solemnes sobre un nuevo término que desde entonces va adquirir carta de naturaleza en la jerga referida a ese pasado: $m e$ moria histórica ${ }^{41}$.

Pero de todas esas disposiciones legales, algunas ya referidas con anterioridad, cabe destacar la ley 52/2007 «Por la que se reconocen y amplían derechos y se establecen medidas a favor de quienes padecieron persecución o violencia durante la guerra civil y la dictadura ${ }^{42}$, conocida popularmente como ley de Memoria Histórica. Fue aprobada sin consenso entre los diferentes partidos políticos que conformaban el arco parlamentario español. Falta de entendimiento que constituyó un negativo precedente para una ley que desde sus inicios se ha visto envuelta en la controversia ${ }^{43}$.

40 Diario de Sesiones del Congreso de Diputados, Comisión Constitucional, 20-XI2002.

41 Pérez Garzón y Manzano Moreno, 2010.

42 BOE, 27-XII-2007.

${ }^{43}$ Escudero, 2011. 


\section{Cuadro 2}

Legislación estatal sobre las consecuencias de la Guerra Civil (años 2000-2010)

\begin{tabular}{|c|c|c|}
\hline Procedencia & Fecha & Contenido \\
\hline $\begin{array}{l}\text { Ministerio de Presi- } \\
\text { dencia. Real Decreto } \\
\text { 1891/2004 }\end{array}$ & BOE 20-IX-2004 & $\begin{array}{l}\text { Creación de la Comisión Interministerial } \\
\text { para el estudio de las víctimas de la Guerra } \\
\text { Civil y el Franquismo. }\end{array}$ \\
\hline $\begin{array}{l}\text { Jefatura del Estado. } \\
\text { Ley } 3 / 2005\end{array}$ & BOE 21-III-2005 & $\begin{array}{l}\text { Reconocimiento de prestación económica a } \\
\text { los ciudadanos de origen español desplaza- } \\
\text { dos al extranjero durante su minoría de edad, } \\
\text { como consecuencia de la guerra civil, que } \\
\text { desarrollaron la mayor parte de su vida fuera } \\
\text { del territorio nacional. }\end{array}$ \\
\hline $\begin{array}{l}\text { Jefatura del Estado. Ley } \\
21 / 2005\end{array}$ & BOE 18-II-2005 & $\begin{array}{l}\text { Restitución a la Generalitat de Cataluña de } \\
\text { los documentos depositados en el Archivo } \\
\text { General de la Guerra Civil Española. }\end{array}$ \\
\hline $\begin{array}{l}\text { Jefatura del Estado. Ley } \\
21 / 2006\end{array}$ & BOE 8-VII-2006 & $\begin{array}{l}\text { Declaración del año } 2006 \text { como año de la } \\
\text { Memoria Histórica. }\end{array}$ \\
\hline $\begin{array}{l}\text { Ministerio de Cultura. } \\
\text { Real Decreto 697/2007 }\end{array}$ & $B O E$ 15-VI-2007 & $\begin{array}{l}\text { Creación del Centro Documental de la Me- } \\
\text { moria Histórica. }\end{array}$ \\
\hline $\begin{array}{l}\text { Jefatura del Estado. } \\
\text { Ley } 52 / 2007\end{array}$ & $\begin{array}{ll}B O E & 27-\mathrm{XII}- \\
2007 & \end{array}$ & $\begin{array}{l}\text { Ley por la que se reconocen y amplían de- } \\
\text { rechos y se establecen medidas a favor de } \\
\text { quienes padecieron persecución o violencia } \\
\text { durante la guerra civil y la dictadura. }\end{array}$ \\
\hline $\begin{array}{l}\text { Ministerio de Justicia. } \\
\text { Real Decreto 1791/2008 }\end{array}$ & BOE 17-XI-2008 & $\begin{array}{l}\text { Declaración de reparación y reconocimien- } \\
\text { to personal a quienes padecieron persecu- } \\
\text { ción o violencia durante la guerra civil y la } \\
\text { dictadura. }\end{array}$ \\
\hline $\begin{array}{l}\text { Ministerio de Justicia. } \\
\text { Real Decreto 1792/2008 }\end{array}$ & BOE 17-XI-2008 & $\begin{array}{l}\text { Concesión de nacionalidad española a los } \\
\text { voluntarios integrantes de las Brigadas Inter- } \\
\text { nacionales }\end{array}$ \\
\hline $\begin{array}{l}\text { Ministerio de Cultura. } \\
\text { Real Decreto 2134/2008 }\end{array}$ & BOE 10/I/2009 & $\begin{array}{l}\text { Se regula el procedimiento a seguir para la } \\
\text { restitución a particulares de los documentos } \\
\text { incautados con motivo de la guerra civil. }\end{array}$ \\
\hline $\begin{array}{l}\text { Ministerio de la Presi- } \\
\text { dencia. Real Decreto } \\
\text { 1816/2009 }\end{array}$ & BOE 24/III/2010 & $\begin{array}{l}\text { Aprobación del reglamento de los Archivos } \\
\text { Judiciales Militares. }\end{array}$ \\
\hline
\end{tabular}

Fuente: Hernández Castrillo (ed.). 
Y es que desde su aprobación ha sido objeto de críticas no solo por parte de las formaciones políticas, sino también de los cuerpos asociativos memorialistas que no veían sus demandas debidamente representadas en su articulado. Desavenencias hacia un texto que en su puesta en funcionamiento ha destacado por su lentitud. Todo ello a pesar de encontrarnos ante una Ley que supuso un nuevo marco jurídico y social en relación al reconocimiento y reparación de las víctimas de la represión en la guerra civil y dictadura ${ }^{44}$.

Pero independientemente de lo polémico de su aprobación y demora en su puesta en práctica, haremos referencia a continuación a algunos de sus contenidos. Resaltamos entre éstos su artículo 15 relativo a símbolos y monumentos públicos, que hace alusión a la retirada de «escudos, insignias, placas y otros objetos o menciones conmemorativas de exaltación, personal o colectiva, de la sublevación militar, de la Guerra Civil y de la represión de la Dictadura», propiedad de la Administración General del Estado y sus organismos públicos dependientes.

Con ese fin, desde el ministerio de Cultura y mediante Orden 459/2009 ${ }^{45}$, se procedió a crear la Comisión Técnica de Expertos para la valoración de los supuestos determinantes de la excepcionalidad en la retirada de símbolos. La integraban técnicos de la administración y expertos de procedencia histórica, artística y arquitectónica, consistiendo su misión principal en seleccionar y determinar los símbolos y objetos que no debían ser retirados por razones artísticas, arquitectónicas o artístico-religiosas que no «supusiesen exaltación alguna a la sublevación militar, guerra civil y dictadura».

Para facilitar su cometido cada Ministerio realizó un inventario de los vestigios existentes en cada una de sus dependencias y sobre ellos se trabajó, recogiéndose las actuaciones de la Comisión en el siguiente informe:

«Desde su creación, la comisión de expertos ha mantenido catorce reuniones plenarias en las que se han analizado 705 vestigios procedentes de trece ministerios y otros organismos de la Administración General del Estado. El análisis se ha realizado a través de documentos e imágenes facilitadas por los ministerios, así como por el examen in situ o por medio de informes técnicos especializados. Hasta finales de abril de

44 Martín y Escudero, 2007.

45 BOE, 28-II-2009. 
2011 se tiene constancia de la retirada de unos 570 vestigios. El resto está en proceso de tramitación, bien porque requiere un procedimiento administrativo largo o por su coste. El ministerio que más vestigios presentaba en sus dependencias era el de Defensa, del que se han retirado más de 400 símbolos.» ${ }^{46}$

Labor, como puede apreciarse, que supuso la retirada de mas de medio millar de símbolos. Resultados que ponen de manifiesto el alcance que ha tenido la puesta en práctica de esta Ley en relación a cuestión tan controvertida ${ }^{47}$. E igualmente es preciso señalar que esta Comisión, y es una cuestión que apenas ha tenido trascendencia pública, antes de la creación por el Gobierno presidido por el socialista José Luis Rodríguez Zapatero de la Comisión de Expertos del Valle de los Caídos, en mayo de 201148, también intervino en relación a este lugar de memoria franquista.

Como monumento dependiente de Patrimonio Nacional, sus miembros visitaron Cuelgamuros y elevaron el correspondiente informe sobre su situación y actuaciones futuras a realizar, haciéndolo seguir al Ministerio de Cultura. En el mismo se recogían propuestas con los siguientes contenidos:

- Es pertinente conservarlo por su valor histórico y simbólico.

- Eliminación de la denominación Valle de los Caídos y en su lugar poner: Conjunto Monumental de Cuelgamuros.

- Desafectación y desacralización del edificio.

- Creación en él un centro de interpretación sobre la represión en el régimen franquista.

- Conversión del conjunto monumental en un lugar de memoria de todas las víctimas de la contienda armada y dictadura

- Dar la mayor dignidad y visibilidad posible a todos los cadáveres depositados en sus dependencias.

46 «Balance general de la retirada de vestigios de la Administración General del Estado», Ministerio de Cultura, 2011. www.memoriahistorica.gob.es/es-es/vestigios

${ }^{47}$ Citamos como ejemplo la retirada de la estatua ecuestre de Franco de la madrileña plaza de San Juan de la Cruz, en marzo de 2005, que fue recurrida por la Fundación Francisco Franco y un particular, y que en su sentencia el Tribunal Superior de Justicia de Madrid determinó que el Ministerio de Fomento no siguió los cauces legales adecuados para retirar la estatua, pero rechazó que deba ser recolocada «porque la Ley de la Memoria Histórica lo prohíbe». Diario Público, 3-III-2009.

48 Boletín Oficial del Estado, 28-V-2011. 
En suma, se recomendaban una serie de actuaciones que tuvieron como principal característica haber sido elaboradas y presentadas meses antes del informe confeccionado por la referida Comisión, que no fue entregado con sus conclusiones al ministerio de Presidencia hasta el 29 de noviembre de $2011^{49}$.

Y en esa misma línea de argumentación deseamos subrayar las referencias a las exhumaciones de fosas contenidas en la Ley 52/2007, concretamente en sus artículos números 11 al 14. En concreto se solicitaba a las administraciones públicas colaboración con las familias en la búsqueda de desaparecidos violentamente, concediendo las preceptivas autorizaciones para desarrollar las prospecciones destinadas a la localización y traslado de restos, abriendo la posibilidad de una ocupación temporal de los terrenos a explorar.

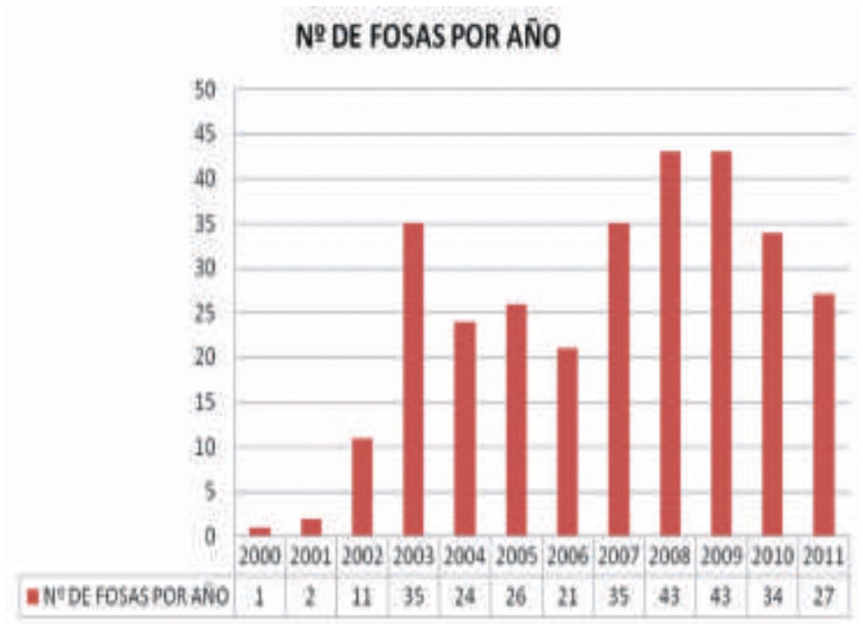

\section{Gráfico 1}

Exhumaciones realizadas en España desde el año 2000

Fuente: Etxebarría Gabilondo, F. ${ }^{50}$

49 Véase contenido íntegro de este informe: http://digital.csic.es/handle/10261/85710

50 Ibidem, pp. 13-28 (p. 14 para esta cita). 
Nuevo escenario sobre un contenido novedoso que demandaba jurisprudencia para poder acometerlo con todas las garantías. Destacamos en ese sentido el acuerdo en Consejo de Ministros, casi cuatro años después de la aprobación de esta Ley, de la puesta en marcha del protocolo de actuación en exhumaciones de víctimas de la guerra civil y la dictadura. Formalidad indispensable para en lo sucesivo poder regular tanto las exhumaciones como los análisis forenses. Como afirma el antropólogo forense Francisco Etxeberría: «este protocolo traslada una buena parte de la competencia de la investigación al ámbito de la Antropología y Patología Forense en el marco general de las Ciencias Forenses» ${ }^{51}$.

Sin embargo, si importante era esa decisión pese a su tardanza, lo cierto es que desde inicios de siglo las exhumaciones habían registrado un especial incremento en todo el país, como puede a preciarse en el cuadro que se acompaña. Significativa evolución que a buen seguro constituyó uno de los argumentos de mayor peso específico para que los políticos trataran de sacar adelante la Ley de Memoria Histórica. Junto a ello también resultó determinante el movimiento asociativo memorialista que acompañó a las demandas de exhumación.

Y en ese sentido es preciso destacar la importancia del movimiento ciudadano registrado en España desde inicios del presente siglo protagonizado por familiares de víctimas del franquismo representados por esas asociaciones. Colectivos que han exigido dignidad y reconocimiento con los vencidos en la guerra civil, con iniciativas destinadas a estimular la conciencia ciudadana acerca de las consecuencias de las prácticas represivas franquistas y el deliberado olvido al que han sido sometidas sus víctimas ${ }^{52}$.

Las exhumaciones se convirtieron en el buque insignia de sus reivindicaciones, coadyuvando sus demandas a presionar al Ejecutivo a aprobar la Ley objeto de análisis. Texto legal que en su articulado contempla la elaboración de un mapa de fosas de los territorios en que se habían llevado a cabo exhumaciones, que como ha sucedido con otros contenidos, se presentó años después, concretamente en la primavera de $2011^{53}$.

51 Etxeberría, 2012,pp. 13-28 (p. 17 para esta cita).

52 Córcoles, 2010, pp. 419-428 (p. 424 para esta cita).

${ }^{53}$ En su reparto geográfico, este mapa recoge las exhumaciones que han realizado en todo el territorio español, aportando también, cuando existen datos al respecto, la identificación de las personas allí enterradas. Asimismo registra como novedad que abarca a todo el territorio español, aunque en absoluto fue pionero pues para entonces ya existían mapas de fosas comunes identificadas y exhumadas en comunidades autónomas como la del País 
Y en esa lentitud en su puesta en práctica se encuentran parte de las razones que condujeron al entonces juez de la Audiencia Nacional, Baltasar Garzón, a promulgar el 16 de octubre de 2008 un Auto por el que se declaraba competente en casos de crímenes contra la humanidad cometidos por el franquismo ${ }^{54}$. Incoaba esta causa a instancia de las asociaciones y familiares, y entre sus objetivos destacaba el esclarecimiento de la desaparición de 114.000 personas a causa de la represión practicada por el bando franquista durante la guerra y régimen posterior ${ }^{55}$. Sin embargo, aunque este juez se inhibió previamente, lo cierto es que este Auto no prosperó ante la oposición al mismo del Pleno de la Sala de lo Penal de la Audiencia que lo declaró nulo.

Con posterioridad Garzón fue denunciado por el Sindicato «Manos Limpias», bajo la acusación de haber cometido con este Auto un delito de «prevaricación», al considerar que vulneraba los preceptos de la ley de Amnistía de 1977. La denuncia fue admitida a trámite por el Tribunal Supremo y la vista tuvo lugar en febrero de 2012, resultando absuelto. En la sentencia del alto tribunal se indica que «Garzón incurrió en un error, como es calificar los hechos como crímenes contra la humanidad y que de ahí cuelgan los demás errores cometidos por el exmagistrado, aunque esos errores no constituyen delito de prevaricación ${ }^{56}$.

Vasco, Cataluña, Andalucía o Extremadura. Véase el mapa en cuestión en la web del Gobierno de España: http://www.memoriahistorica.gob.es/es-es/mapafosas/paginas/index.aspx

54 Penella, 2010.

55 El Auto del Juzgado Central de Instrucción n. ${ }^{\circ} 5$ de la Audiencia Nacional en Madrid constaba de 68 páginas y tenía como base las denuncias presentadas a este Juzgado desde el 14 de diciembre de 2006 hasta la fecha del Auto, todas por presuntos delitos de «detención ilegal», fundamentadas en «la existencia de un plan sistemático y preconcebido de eliminación de oponentes políticos a través de múltiples muertes, torturas, exilio y desapariciones forzadas (detenciones ilegales) de personas a partir de 1936, durante los años de Guerra Civil y los siguientes de la posguerra, producidos en diferentes puntos geográficos del territorio español (...)». EL PAIS, 16-X-2008.

56 Además cabe destacar que la sentencia critica, entre otros aspectos, los juicios de la verdad «porque si bien en Argentina y otros países se puede realizar una investigación para acreditar lo ocurrido, en España solo es posible realizar una investigación cuando existe una persona física a la que investigar y en este caso es obvio que todos los ministros de Franco que Garzón incluyó como presuntos imputados en el plan sistemático de exterminio puesto en marcha durante la guerra estaban ya muertos». También aclara que «los historiadores tienen su papel y que los jueces tienen el suyo y no se pueden mezclar». EL PAIS, 27-II-2012. 
Hechos y resultados de un proceso que al igual que otros que han afectado a este magistrado se han visto acompañados por una cobertura mediática desproporcionada. En realidad todo lo relacionado con la denominada «memoria histórica» desde inicios del presente siglo ha tenido una destacada resonancia en los medios de comunicación. Sus implicaciones sociales, las controvertidas visiones históricas, las demandas de las distintas asociaciones y la respuesta política han contribuido a esa repercusión en los medios. Consideramos que esa respuesta es reflejo del alcance de esta cuestión en la España actual, que en absoluto cabe analizar en términos exclusivamente históricos pues como pretendemos exponer en este trabajo, consideramos que tiene otros componentes que le dan unas dimensiones sociales de indudable trascendencia entre la ciudadanía ${ }^{57}$.

\section{Leyes de Memoria Histórica en algunas comunidades autónomas}

Y junto a las iniciativas estatales anteriormente expuestas cabe destacar otras de ámbito regional que no se circunscribieron sólo a este tipo de cuestiones sino que se extendieron a otros aspectos de no menor tenor, en un claro deseo de contar con una legislación propia con la que completar las carencias que a su juicio presentaba la Ley de Memoria Histórica. Así cabe entender las iniciativas que sobre esta materia se han registrado en los últimos años en algunas comunidades autónomas, generalmente regidas por gobiernos no conservadores.

En el cuadro que se expone al respecto puede apreciarse que cuando se terminó de redactar este artículo, en cinco ámbitos territoriales ya han sido aprobadas leyes de «memoria histórica» y en dos existen proyectos pendientes de ser debatidos en sus parlamentos. Igualmente hay entes autonómicos que se encuentran trabajando en la elaboración de sus respectivas leyes, como es el caso de Canarias y Cantabria ${ }^{58}$. También ha habido otras actuaciones, como la abanderada desde el Gobierno del País Vasco, que han completado lo legislado con otras iniciativas ${ }^{59}$.

57 Escudero, 2011.

${ }^{58}$ En Canarias, el grupo de trabajo creado para este fin sigue perfilando el texto, aunque sin dar todavía fechas para su presentación. Y en Cantabria, el Ejecutivo asegura tener ya lista una primera versión del borrador, que quieren ir completando ahora con las propuestas de los colectivos memorialistas. InfoLibre, 4-VI-2017.

59 En esas coordenadas cabe encuadrar la Ley 4/2014, de 27 de noviembre, de creación del Instituto de la Memoria, la Convivencia y los Derechos Humanos (BOE, 19-XII- 


\section{Cuadro 3}

Comunidades autónomas: leyes de «memoria histórica»

\begin{tabular}{|c|c|c|}
\hline $\begin{array}{c}\text { Comunidad } \\
\text { Autónoma }\end{array}$ & Situación & Denominación \\
\hline Cataluña & $\begin{array}{l}\text { Ley } 10 / 2009, \text { de } 30 \text { de junio, } \\
B O E 3 \text { de agosto de } 2009 .\end{array}$ & $\begin{array}{l}\text { Ley sobre la localización e identifi- } \\
\text { cación de las personas desaparecidas } \\
\text { durante la Guerra Civil y la dictadura } \\
\text { franquista, y la dignificación de las } \\
\text { fosas comunes. }\end{array}$ \\
\hline Navarra & $\begin{array}{l}\text { Ley foral } 33 / 2013 \text {, de } 26 \text { de } \\
\text { noviembre, } B O E 20 \text { de diciem- } \\
\text { bre de } 2013 \text {. }\end{array}$ & $\begin{array}{l}\text { Ley de reconocimiento y reparación } \\
\text { moral de las ciudadanas y ciudadanos } \\
\text { navarros asesinados y víctimas de la } \\
\text { represión a raíz del golpe militar de } \\
1936\end{array}$ \\
\hline Islas Baleares & $\begin{array}{l}\text { Ley } 10 / 2016 \text {, de } 13 \text { de junio, } \\
B O E 30 \text { de junio de } 2016 .\end{array}$ & $\begin{array}{l}\text { Ley para la recuperación de personas } \\
\text { desaparecidas durante la guerra civil } \\
\text { y el franquismo. }\end{array}$ \\
\hline Andalucía & $\begin{array}{l}\text { Ley } 2 / 2017, \text { de } 28 \text { de marzo, } \\
B O E 21 \text { de abril de } 2017 .\end{array}$ & $\begin{array}{l}\text { Ley de Memoria Histórica y Demo- } \\
\text { crática de Andalucía }\end{array}$ \\
\hline $\begin{array}{l}\text { Comunid ad } \\
\text { Valenciana }\end{array}$ & $\begin{array}{l}\text { Ley } 14 / 2017 \text { del Gobierno Va- } \\
\text { lenciano, BOE } 23 \text { de diciembre } \\
2017 .\end{array}$ & $\begin{array}{l}\text { Ley de Memoria Democrática y para } \\
\text { la Convivencia de la Comunidad Va- } \\
\text { lenciana }\end{array}$ \\
\hline Aragón & $\begin{array}{l}\text { Ley } 14 / 2018 \text {, de } 8 \text { de noviem- } \\
\text { bre de } 2018, B O E \text { 16-I-2019. }\end{array}$ & $\begin{array}{l}\text { Ley de Memoria Democrática de } \\
\text { Aragón }\end{array}$ \\
\hline Extremadura & $\begin{array}{l}\text { Ley } 1 / 2019 \text {, de } 21 \text { de enero de } \\
2018, \text { DOE } 24-\mathrm{I}-2019 .\end{array}$ & $\begin{array}{l}\text { Ley de Memoria Histórica y Demo- } \\
\text { crática de Extremadura }\end{array}$ \\
\hline
\end{tabular}

Fuentes: BOE y DOE

2014), o el Plan de Paz y Convivencia 2013-2016, que en su programa base de prioridades en el bienio 2015-2016 expone un mapa de fosas comunes a causa de la represión franquista en Euskadi. www.euskadi.eus/mapa-fosas/web01-sllehmem/es/ Asimismo el Plan Vasco 2015-20 de Investigación y Localización de Fosas «para la búsqueda e identificación de personas desaparecidas durante la guerra civil». www.bibliotekak.euskadi. eus/WebOpac 
Es preciso resaltar que el nexo de unión de todas estas leyes autonómicas lo constituye su deseo de cubrir algunas de las insuficiencias de la normativa estatal ${ }^{60}$, especialmente en lo referido a la localización e identificación de las víctimas, exhumación de fosas comunes, reparación y reconocimiento. En torno a esta cuestión, junto a otras complementarias, se han elaborado unos textos legislativos que sobre todo tratan de responder a las reivindicaciones de los familiares de las víctimas y las asociaciones que les representan y, por ende, al conjunto de la sociedad. También obedecen a la petición de organizaciones políticas y sindicales para que los parlamentos procediesen a aprobar leyes que superasen las limitaciones de orden sustantivo y procedimental que a su juicio presentaba la Ley 52/2007.

En relación a ese contenido, en líneas generales esta legislación autonómica es coincidente en la necesidad de conocer el alcance de la represión política, ideológica, educativa y cultural a causa de la guerra civil y el franquismo, conminando al desarrollo de investigaciones que permitan conocer la identidad de las personas desaparecidas y también, en los casos en que se desconozca, su paradero. Proceso que como se ha indicado con anterioridad en algunas provincias españolas tuvo su punto de partida en la década de los ochenta del pasado siglo, teniendo sucesión de continuidad con posterioridad. Estudios que han supuesto, junto a otros más recientes, la base para elaborar los preceptivos censos de personas afectadas por las diferentes tipologías represivas

Y junto a la identificación, se insiste de forma precisa en dar un impulso definitivo a la localización y exhumación de fosas comunes pendientes de intervenir. Trabajos que deben verse acompañados, cuando las condiciones y medios lo permitan, con el esclarecimiento de la identidad de los restos pertenecientes a cada víctima y su entrega a los familiares o entidad pública procedente en caso de ausencia de éstos. Proceso de exhumaciones que es descrito con detalle en todas estas leyes, en el convencimiento que este contenido justifica por sí mismo su aprobación.

E insistimos en este apartado de las exhumaciones por resultar clave en la legislación autonómica. Pionera en su tratamiento fue la aprobada en Cataluña en junio de $2009^{61}$, que en su preámbulo dejaba meridianamente claro su objetivo principal:

60 Cuesta y Odriozola, 2018, pp. 1-38.

${ }^{61}$ En relación a estos contenidos, en 2016 la Generalitat de Cataluña ha aprobado el Programa de Identificación Genética de las personas desaparecidas durante la guerra civil y 
«Prioritario de esta ley es localizar y, si procede, recuperar e identificar los restos de las personas, tanto civiles como militares, que desaparecieron y de las que fueron ejecutadas y enterradas en fosas comunes durante la guerra civil y dictadura franquista, para reconocer su dignidad con independencia de las opciones ideológicas, personales o de conciencia que las hicieron víctimas de la represión. Para cumplir dicho objetivo, procede crear el marco jurídico y los mecanismos necesarios para localizar e identificar a las personas desaparecidas: entre otros, un censo de personas desaparecidas, mapa de fosas y medidas para señalizar y dignificar espacios $(\ldots) .{ }^{62}$

Planteamientos que prácticamente se han repetido en las restantes leyes, como lo demuestra que en la mayoría de ellas, en su artículo primero dedicado al «objeto» de esta ley, inciden en la necesidad de localizar a las víctimas y, si procede, recuperar e identificar sus restos. Citamos a ese respecto lo recogido por la Ley aprobada en la Comunidad Autónoma de las Islas Baleares, que contempla: «Establecer las pautas para la regulación de las actividades de localización, identificación y señalización de fosas y lugares donde se produjeron muertes violentas por razones de ideología, políticas y religiosas de la guerra civil y la dictadura franquista en el territorio de la comunidad autónoma y, si es posible, su exhumación» ${ }^{63}$.

Con ese fin se establecen las obligaciones de las comunidades autónomas para con las desapariciones y las exhumaciones, concediéndoles plenas competencias en esta materia. Atribuciones que tratan de resolver las carencias que la Ley estatal presenta en relación a estos cometidos e incluso con nuevas iniciativas. Resaltamos en relación a ello la ley foral 33/2013 de Navarra, que en el capítulo sobre las obligaciones de las administraciones públicas sobre los desaparecidos, en su artículo 8 contempla la creación de un Banco de ADN, dependiente del Instituto Legal de Navarra, con el fin de conservar muestras de restos óseos de las distintas exhumaciones realizadas en su territorio, con su secuencia de ADN.

la dictadura franquista, con el fin de crear una base de datos de los perfiles genéticos de los familiares de desaparecidos y de los restos humanos exhumados. Generalitat de Cataluña. Subdirección General de la Memoria. www.exteriors.gencat.cat/identificaciongenetica

62 BOE, 3-VIII-2009, p. 66.162.

${ }^{63}$ Llama la atención en esta escueta ley que contiene una exposición de motivos tan extensa como los doce artículos que la componen. BOE, 30-VI-2016, p. 4. 
Comunidad Autónoma de Navarra que al igual que lo sucedido en la estatal, también asistió al retraso en la puesta en funcionamiento de referida Ley, que no se ha empezado a activar decididamente hasta el cambio de Gobierno tras la elecciones de 2015. Demora que sin embargo no ha impedido llevar a cabo en su territorio exhumaciones tan señeras como la que tuvo lugar en el cementerio de la prisión del Fuerte de San Cristóbal, en el monte Ezkaba, iniciada en 2007 y que se prolongó durante los tres años siguientes. El balance de esa actuación, iniciada un sexenio antes de aprobarse esta Ley, supera el centenar de exhumaciones de presos «que nunca regresaron a sus casas y murieron por las malas condiciones higiénico-sanitarias, el abandono y por el hambre de una posguerra atroz para quienes habían defendido la legalidad republicana ${ }^{64}$.

En Andalucía también se dedica una parte significativa de su articulado a las exhumaciones. Y al igual que en la de Navarra, en su artículo 13 recoge que sea la Administración de la Junta de Andalucía la encargada de realizar las pruebas genéticas que permitan la identificación de los restos óseos exhumados». A tal fin «establecerá y gestionará un sistema de banco de datos de ADN en colaboración con las universidades públicas de Andalucía, en el que se registrarán tanto los datos de los restos óseos exhumados como el ADN de personas voluntarias que, tras su acreditación, deseen formar parte de este banco de datos por su condición de familiares víctimas» ${ }^{65}$.

Avances y acotaciones a la normativa estatal en una comunidad autónoma que desde hace años ha contado con un Comisariado de la Memoria Histórica y mostrado una especial actividad en atención a las víctimas en todo su territorio, el más castigado de España en cuanto a número de defunciones a causa de la represión franquista ${ }^{66}$. Y dentro de ese capítulo ha venido dedicando una especial atención a las exhumaciones de fosas, con la publicación de anuarios sobre el ingente número de intervenciones practicadas en toda su geografía regional ${ }^{67}$.

Actuaciones en tierras andaluzas que han sido cuestionadas por determinados grupos políticos, como lo pone de manifiesto el acuerdo firmado

\footnotetext{
${ }^{64}$ Herrasti y Etxeberría, 2014, pp. 113-152.

65 BOE, 21-IV-2017, p. 17.

${ }^{66}$ Cobo, 2012.

67 Baquero, 2016.
} 
entre las formaciones Vox y Partido Popular, para investir al líder de esta última como presidente de esa Comunidad tras las elecciones a su Parlamento de 2 de diciembre de 2018. En concreto, en el apartado 33 de ese pacto se recoge de forma implícita: «Promover una Ley de Concordia que sustituya la Ley de Memoria Histórica» ${ }^{68}$. Decisión de indudable alcance político que pone de manifiesto la inequívoca actualidad del objeto de estudio en este artículo.

Y respecto al estado en que se encuentra esa legislación en otras comunidades autónomas, es preciso indicar que desde finales de 2017 la Valenciana ya cuenta con su correspondiente Ley de Memoria Democrática y para la Convivencia y, un año después, lo mismo podemos decir en la de Aragón. En Extremadura, su Parlamento aprobó la Ley de Memoria Histórica y Democrática en pleno celebrado el 20 de diciembre de 2019, con los votos del PSOE y Podemos, en contra del Partido Popular y abstención de Ciudadanos ${ }^{69}$.

Leyes que contemplan en su articulado un tratamiento profuso y detallado en relación a las exhumaciones de fosas comunes. E igualmente su finalidad, como se recoge en la exposición de motivos de la extremeña, es dar respuesta a las lagunas que presenta la Ley 52/2007: «sobre todo en materia de justicia y reparación de los daños causados a los represaliados por el franquismo y la necesidad de ofrecerle una cobertura jurídica propia, compatible con la Ley de Memoria Histórica pero ajustada también a la legislación y acuerdos internacionales en materia de respeto a los derechos humanos suscritos por España» ${ }^{70}$.

Legislación que en su conjunto, además de la cuestión nuclear de las exhumaciones, presenta en sus diferentes apartados otras cuestiones de no menor interés. Es el caso del reconocimiento, rehabilitación y dignificación a las personas que sufrieron represión por parte del régimen franquista. Víctimas, prisioneros, sentenciados, exiliados, afectados por sanciones de naturaleza económica y, en general, todas las personas y familias objeto de este tipo de acciones componen este extenso capítulo por el que la mayoría de estas leyes tratan de reparar su honor y reconocer las vicisitudes que atravesaron a consecuencia de estas acciones violentas.

68 EL PAIS, 10-I-2019

69 El Periódico Extremadura, 20-XII-2018.

70 Diario Oficial de Extremadura, 24-I-2019. . 
Se añaden a esta serie de cuestiones otras de no menor relieve como la retirada de símbolos o la prohibición de actos de conmemoración o enaltecimiento alusivos a la sublevación de julio de 1936 y régimen posterior, encomendando a las administraciones públicas que velen por el cumplimiento de estas disposiciones. Igualmente se hace hincapié en la preservación de los denominados «lugares de memoria» ${ }^{71}$, es decir inmuebles 0 parajes vinculados con la represión que sufrió la población durante la contienda armada y dictadura. También a cuestiones educativas y, en algunos casos, la anulación de juicios franquistas.

Abanico temático que evidencia la apuesta de algunas comunidades autónomas por aprobar leyes específicas de «memoria histórica», mientras que en otras se ha optado por otras alternativas legales. Es el caso de Euskadi que carece de una ley vasca de memoria histórica ${ }^{72}$, pese a venir legislando sobre la materia desde los años ochenta ${ }^{73}$. O el Gobierno de la Comunidad Autónoma de Castilla y León que optó por aprobar un Decreto de Memoria Histórica y Democrática ${ }^{74}$. Diversidad legislativa extensible a otros territorios que muestra la sensibilidad de ciertos gobiernos autónomos por situar este contenido entre las prioridades de sus políticas públicas.

\section{Consideraciones finales}

A modo de conclusión es preciso señalar que como hemos podido apreciar desde la Transición se ha venido aprobando en España un corpus legislativo de diferente procedencia y condición, destinado a paliar las consecuencias que sobre un sector de la ciudadanía tuvo el pasado traumático representado por la guerra civil y régimen político posterior. Leyes y decretos que tuvieron durante los inicios de la democracia una ralenti-

71 García, 2009, pp. 175-202.

72 Ley que ha sido demandada por formaciones políticas como el PSE-EE, que a través de su secretaria Idoia Mendia ha reivindicado una ley vasca de Memoria Histórica que «desde nuestras competencias, complemente la vigente norma en España». eldiario.es, 26-I-2019.

73 http://www.euskadi.eus/contenidos/informacion/memoria_presentacion_antecende/ es_def/index.shtml

${ }^{74}$ Decreto 9/2018. Boletín Oficial de Castilla y León, 16-IV-2018. 
zación justificada a instancias politicas por la necesidad de atender otras cuestiones consideradas más perentorias.

Dinámica que ha sufrido significativa modificación con el inicio del siglo actual ante las exigencias de un sector de la población y cuerpos asociativos que les representan de medidas legales para dar respuesta a ese pasado traumático con las garantías que ofrece un Estado democrático consolidado. Y dentro de esas reivindicaciones, el principal foco de atención ha sido la existencia en suelo español de fosas comunes sin exhumar de represaliados por el franquismo.

Todo este movimiento social que gira en torno a la memoria histórica ha exigido soluciones y la principal iniciativa en un plano estatal fue la aprobación de la Ley 52/2007. Texto legal que nació sin consenso político y ha estado marcado por la polémica desde sus inicios. La demora en su puesta en funcionamiento ha tenido mucho que ver con ese origen tan controvertido, como también las evidentes insuficiencias que presenta en su contenido especialmente en materia de exhumaciones de fosas comunes.

Insuficiencias a las que se ha tratado de dar respuesta desde algunas comunidades autónomas regidas, por lo general, por formaciones políticas no conservadores, que guiadas por los principios de verdad, justicia, reparación y garantías de no repetición, aconsejados por la legislación y acuerdos internacionales defensores de los derechos humanos, han impulsado la aprobación de leyes capaces de suplir en sus preceptos jurídicos las carencias de la Ley estatal.

Legislación en los últimos años que ha puesto de manifiesto lo pertinente de su aprobación con vistas a dar cumplida respuesta a las demandas de un sector de la ciudadanía. Y es que más allá de la politización a que generalmente se ve expuesta la cuestión de la memoria histórica y su utilización partidaria según propias conveniencias, se impone una correcta aplicación de estas leyes con vistas a clarificar actuaciones y tratar de zanjar asignaturas pendientes tan lacerantes como la existencia de fosas comunes sin exhumar en el territorio español, pese a que han transcurrido ocho décadas desde la finalización de la guerra civil.

\section{Fuentes}

Boletín Oficial del Estado

Archivos Municipales

Diario de Sesiones del Congreso de Diputados, Comisión Constitucional 
web del Gobierno de España: http://www.memoriahistorica.gob.es www.euskadi.eus/mapa-fosas/web01-s1lehmem/es/ www.bibliotekak.euskadi.eus/WebOpac www.exteriors.gencat.cat/identificaciongenetica http://estaticos.soitu.es/documentos/2008/10/auto_memoria_historica.pdf

\section{Bibliografía}

Aguilar, Paloma, Políticas de la memoria y memorias de la política. El caso español en perspectiva comparada, Alianza Editorial, Madrid, 2008.

BAquero, Juan Miguel, Que fuera mi tierra. Anuario 2015. Intervenciones en fosas comunes del franquismo en Andalucía, Junta de Andalucía, Sevilla, 2016.

CoBo Romero, Francisco (coord.), La represión franquista en Andalucía. Balance historiográfico, perspectivas teóricas y análisis de resultados, Centro de Estudios Andaluces, Sevilla, 2012.

CórColes, Ángeles, «Las heridas del silencio. El silencio des-trama», Revista Electrónica de Psicoterapia Clínica e Investigación Relacional, vol. IV (2), 2010, pp. 419-428.

Cuesta, Josefina, La odisea de la memoria. Historia de la memoria en España siglo XX, Alianza Editorial, Madrid, 2008.

Cuesta, José Luis de la y Odriozola, Mirien, «Marco normativo de la memoria histórica en España: legislación estatal y autonómica», Revista Electrónica de Ciencia Penal y Criminología, 20-08, 2018, pp. 1-38.

CHAVEs, Julián, La represión en la provincia de Cáceres durante la guerra civil (1936-1939), Universidad de Extremadura, Cáceres, 1995.

CHAves, Julián, «La historiografía reciente sobre la Guerra Civil de 1936-1939 en los umbrales del nuevo milenio», Anales de Historia Contemporánea, 16, 2000, pp. 409-430.

CHAVES, Julián, «La represión en la Guerra Civil: últimas aportaciones bibliográficas y movimientos sociales por la memoria», Pasado y Memoria, 6, 2007, pp. 191-212.

ChAVES, Julián: «Eliminación sistemática de la memoria republicana por el franquismo: de la bandera bicolor al anticomunismo», en CHAVES, Julián, Memoria e investigación en torno al setenta aniversario de la Guerra Civil, Diputación Provincial, Badajoz, 2009, pp. 107-142.

ESCUDERO, Rafael (ed.), Diccionario de memoria histórica. Conceptos contra el olvido, La Catara, Madrid, 2011.

Espinosa MAestre, Francisco, Lucha de historias, lucha de memorias. España, 2002-2015, Aconcagua Libros, Sevilla, 2015. 
Espuny Tomás, María Jesús, Paz Torres, Olga y Ysàs, Pere (eds.), 30 años de la ley de amnistía (1977-2007), Universidad Autónoma de Barcelona, Barcelona, 2007.

ETXEBERRÍA, Francisco, «Exhumaciones contemporáneas en España: las fosas comunes de la guerra civil», Boletín Galego de Medicina Legal e Forense, 18, enero 2012, pp. 13-28.

FERRÁndiz Martín, Francisco, «Exhumaciones y políticas de la memoria en la España contemporánea», Hispania Nova: Revista de Historia Contemporánea, 7, 2007,

GARCíA ÁlvarEZ, Jacobo, «Lugares, paisajes y políticas de memoria: una lectura geográfica», Boletín Oficial de la Asociación Archivo, Guerra y Exilio $(A G E), 51,2009$, pp. 175-202.

Gil GIL, Alicia, La justicia de transición en España. De la amnistía a la memoria histórica, Atelier, Barcelona, 2009.

GonzÁLEZ, Felipe y CEBrián, Juan Luis, El futuro no es lo que era, Aguilar, Madrid, 2001.

GonZÁLEZ RuIBAL, Alfredo, Volver a las trincheras. Una arqueología de la guerra civil, Alianza Editorial, Madrid, 2016.

Hernández CASTRILlo, Santiago (ed.), Recopilación de normativa sobre Memoria Histórica, Ministerio de Justicia, Secretaría General Técnica, Madrid, 2010.

Herrasti, Lourdes y EtXeberría, Francisco, «Exhumación y análisis de los restos del cementerio del Sanatorio Penitenciario de San Cristóbal en el monte Ezkaba (Navarra)», en EtXeberRíA, Francisco y Pla, Koldo (dir.): El cementerio de las botellas. El Fuerte de San Cristóbal en la memoria: de prisión a sanatorio penitenciario, Aranzadi/Pamiela y Trinparta, Pamplona, 2014, pp. 113-152.

Juliá, Santos, «Amnistía como triunfo de la memoria», en EL PAIS, 24-XI-2008.

Martín Pallín, José Antonio y Escudero Alday, Rafael (Eds.): Derecho y Memoria Histórica, Madrid, Trotta, 2007.

Molinero, Carme, «La política de la reconciliación nacional. Su contenido durante el franquismo, su lectura en la Transición», Ayer, 66, 2007 (2), pp. 201-225.

PASAmAr, Gonzalo (ed.), Ha estallado la memoria. La huella de la Guerra Civil en la Transición y Democracia, Biblioteca Nueva, Madrid, 2016.

Penella, M., La causa contra Franco. Juicio al franquismo por crímenes contra la humanidad, Planeta, Barcelona, 2010.

Pérez Garzón, Juan Sisinio y Manzano Moreno, Eduardo, Memoria Histórica, Los Libros de la Catarata, Madrid, 2010.

PÉREZ SERRANO, Julio, «Experiencia histórica y construcción social de las memorias. La transición española a la democracia», Pasado y Memoria. Revista de Historia Contemporánea, 3, 2004, pp. 93-122. 
Pinilla García, Alfonso, La legalización del PCE. La historia no contada. 19741977, Alianza Editorial, Madrid, 2017.

RuIZ, María del Rosario y RIESCO, Sergio, «Veinte años de producción histórica sobre la Guerra Civil española (1975-1985): Una aproximación bibliométrica», Revista Española de Documentación Científica, 2, 1999, vol. 22, p. 183.

Salas Larrazabal, Ramón, Pérdidas de la guerra, Planeta, Barcelona, 1977.

SÁnchez Marroyo, Fernando y Chaves Palacios, Julián: «La doble funcionalidad de una fuente histórica. Los expedientes de orfandad de 1940», en 19361939. La Guerra Civil española, Sociedad Estatal de Conmemoraciones Culturales (Ministerio de Cultura), Madrid, 2008, pp. 101-123.

Soto Carmona, Álvaro y Avilés Ferré, Juan (dir.), Historia de la época Socialista. España. 1982-1996, Sílex, Madrid, 2013.

YsÀs, Pere, «La Transición española. Luces y sombras», Ayer, 79, 2010 (3), pp. 31-57.

\section{Financiación}

Este trabajo se inscribe en el Proyecto Nacional $\mathrm{I}+\mathrm{D}+\mathrm{i}$, referencia HAR2015-64814-P «Hacia la constitución de una nueva sociedad: los mecanismos de control social y político en el primer franquismo», Ministerio de Economía, Industria y Competitividad, dirigido por Julián Chaves Palacios.

\section{Datos del autor}

Julián Chaves Palacios (jchapal@unex.es) es Catedrático Acreditado en Historia por la Universidad de Extremadura, ha publicado más de un centenar trabajos, entre libros, capítulos de libros y artículos en revistas científicas relacionados con la España del siglo XX, principalmente la crisis de los años treinta, Franquismo y Transición política, e Iberoamérica, especialmente las dictaduras del Cono Sur. Desde el año 2005 viene siendo profesor invitado en las Universidades de Santiago de Chile; La Plata, Nacional del Nordeste, Belgrano y Córdoba (Argentina), Paulo Freire (Nicaragua) y UNAM de México, en las que ha impartido docencia a alumnos de postgrado sobre contenidos relacionados con la violencia política contemporánea y derechos humanos. Le fue concedido en 2014 el Doctorado Honoris Causa en Humanidades por la Universidad Paulo Freire, de Nicaragua. 